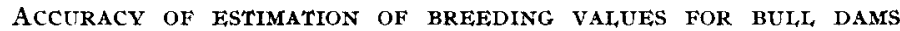 \\ by H. O. Gravert and K. Pabst \\ Institute for Milk Production, Federal Dairy Research Center, Kiel, F.R.G.
}

For I.229 dams of A.I. bulls with known breeding values it was concluded that the accuracy of cow index can be improved only to a limited extend. Accuracy of cow index, measured as correlation between cow index and breeding value of son, did not exceed $r=0.20,0.17$ and 0.12 in first, second and third lactation resp. Improvement of selection intensity seems more promising.

\title{
ESTIMATION OF BREEDING VALUES OF COWS AND OF REI,FVANT PARAMETERS
}

\section{H. HAUSSMANN}

Institut für Tierhaltung und Tievzüchtung der Universität Hohenheim, D-7ooo Stuttgart 7o, Deutschland

One way of improving cow evaluation is to adjust for as many environmental factors as possible. The effects of some factors not usually regarded in prediction procedures have been analyzed and results are presented:

—. interaction between calving season and herd level; multiplicative correction factors for season are suggested;

- interaction between age at calving and herd level; age correction factors depending on herd level are suggested;

- heritability of age at first calving; it is suggested to combine milk yield and age at first calving as traits of economical importance by a selection index;

- parameters depending on herd size; variance components estimated within herd size groups are presented.

\section{CONGORMATION INCLUDED IN A BULL, DAM SELECTION INDEX}

\section{A. FESTERLING}

Institut f. Tierzucht Universitäts Bonn, Bonn, B.R.D.

The bull dam selection index includes in addition to traits such as milk yield, fat content and milking ability, also type and udder conformation scores. The required population parameters have beed estimated from German Friesian cows. The economical weighting of the conformation traits has been applied in relation to milk yield as the most important performance trait. The weighting factor for one standard deviation may reach 20 to $30 \mathrm{p}$. I 00 of the respective value for the milk yield, without reducing the selection response for the remaining traits.

\section{Cow evaluation in SLovenia}

\author{
J. POGAČAR \\ Agricultural Institute of Slovenia, 6tooo Ljubljana, Yugoslavia
}

The paper represents the estimation of breeding values of cows, by which some systematic environmental influences, such as the number of lactations, the calving interval, the herd level and in the large estate farms the calving season as well are excluded. The estimations of the breeding value are made yearly at the time of the last lactation and out of several lactations the average breeding value $(Z W)$ is calculated. The correction factors used for the lactation influence $\left(f_{\mathrm{L}}\right)$ and for the calving interval $\left(f_{\mathrm{DMT}}\right)$ influence are given. 